\title{
(2) OPEN ACCESS \\ Housing affordability effects on physical and mental health: household survey in a population with the world's greatest housing affordability stress
}

\author{
Roger Yat-Nork Chung (D) ,' Gary Ka-Ki Chung (D) ,' David Gordon,' \\ Jonathan Ka-Long Mak, ${ }^{1}$ Ling-Fei Zhang, ${ }^{1}$ Dicken Chan, ${ }^{1}$ Francisco Tsz Tsun Lai (D) , \\ Hung Wong, ${ }^{3}$ Samuel Yeung-Shan Wong ${ }^{1}$
}

\begin{abstract}
- Additional material is published online only. To view please visit the journal online (http://dx.doi.org/10.1136/ jech-2019-212286).

${ }^{1} J \mathrm{C}$ School of Public Health and Primary Care, The Chinese University of Hong Kong, New Territories, Hong Kong ${ }^{2}$ School for Policy Studies, University of Bristol, Bristol, UK ${ }^{3}$ Department of Social Work, Chinese University of Hong Kong, New Territories, Hong Kong
\end{abstract}

\section{Correspondence to} Dr Roger Yat-Nork Chung, Jockey Club School of Public Health and Primary Care, Chinese University of Hong Kong, New Territories, Hong Kong; rychung@cuhk.edu.hk

RY-NC and GK-KC are co-first authors.

Received 15 February 2019 Revised 17 October 2019 Accepted 19 October 2019 Published Online First 5 November 2019

\begin{abstract}
Background We examined the association of housing affordability with physical and mental health in Hong Kong, where there is a lack of related research despite having the worst housing affordability problem in the world, considering potential mediating effect of deprivation.

Methods A stratified random sample of 1978 Hong Kong adults were surveyed. Housing affordability was defined using the residual-income (after housing costs) approach. Health-related quality of life was assessed by the Short-Form Health Survey version 2 (SF-12v2), from which the physical component summary (PCS) and mental component summary (MCS) measures were derived. Multivariable linear regressions were performed to assess associations of housing affordability with PCS and MCS scores, adjusting for sociodemographic, socioeconomic and lifestyle factors. Mediation analyses were also conducted to assess the mediating role of deprivation on the effect of housing affordability on PCS or MCS.
\end{abstract}

Results Dose-response relationships were observed between housing affordability and mean PCS score $(\beta$ $(95 \% \mathrm{Cl})$ compared with the highest affordable fourth quartile: $-2.53(-4.05$ to -1.01$),-2.23(-3.54$ to $-0.92),-0.64(-1.80$ to 0.51$)$ for the first, second and third quartiles, respectively) and mean MCS score ( $\beta$ $(95 \% \mathrm{Cl}):-3.87(-5.30$ to -2.45$),-2.35(-3.59$ to $-1.11),-1.28(-2.40$ to -0.17$)$ for the first, second and third quartiles, respectively). Deprivation mediated $34.3 \%$ of the impact of housing unaffordability on PCS and $15.8 \%$ of that on MCS.

Conclusions Housing affordability affects physical and mental health, partially through deprivation, suggesting that housing policies targeting deprived individuals may help reduce health inequality in addition to targeting the housing affordability problem.

\section{INTRODUCTION}

Housing affordability, defined as the social and material experiences of people in relation to their housing situation, ${ }^{1}$ has become an emerging social issue across the globe. Existing literature generally supports its associations with poorer self-rated health, ${ }^{2-4}$ physical conditions (eg, diminished walking ability, hypertension and arthritis) ${ }^{4}$ and mental health. ${ }^{6-8}$ Specifically, the tradeoff between housing expenses and non-shelter necessities has been recognised as a plausible pathway that links housing unaffordability to poorer health, ${ }^{19}$ where less resources could be allocated to health-promoting necessities such as a balanced diet, healthcare access and maintenance of social networks. ${ }^{510}{ }^{11}$ Despite the apparent tension between housing costs and basic needs, no previous studies have specifically examined the potential mediating role of deprivation of necessities of life on the association between housing affordability and health.

Concerning the methodology to assess housing affordability, the ratio-income approach (ie, housing cost as a proportion of household income with a threshold value specified to indicate unaffordability) is most commonly used. ${ }^{12}$ However, this method fails to measure households' ability to pay for non-shelter necessities, which is likely to differ across income levels given the same proportion of income spent on housing. ${ }^{12}$ The residualincome (after housing costs) approach may be a better indicator of housing affordability ${ }^{13}$ as this measures the absolute amount of income left after housing payments, with a sliding scale in relation to household composition and income levels. ${ }^{12}$ Moreover, it reflects more accurately whether a household could meet its non-housing needs within its income constraint. $^{12}$

Hong Kong serves as an ideal setting to study the association between housing affordability and health as it suffers from severe housing affordability problems despite being one of the most developed places in the world. ${ }^{14}$ In 2018 , the affordability ratio of Hong Kong was the highest in the world at 20.9, meaning that the median cost of a dwelling in Hong Kong is 20.9 times the annual median pretax household income, by contrast the ratios were 8.3 in London, 5.5 in New York and 4.6 in Singapore. ${ }^{14}$ This severe housing affordability stress may have been partially caused by restrictive land use regulations and population growth resulting in a house price bubble since the turn of the millennium. ${ }^{15}$ Despite the population growth from 6.5 to 7.4 million since the early $2000 \mathrm{~s},{ }^{16}$ the area of built-up land increased only by 400 hectares between 2005 and 2015, which was one-fifteenth the increase between 1995 and 2005, ${ }^{17}$ whereas the average annual number of housing completions decreased from 59800 between 1997 and 2006 to 25700 between 2007 and $2016 .{ }^{18}$ On the contrary, the actual income of the general public has only 
increased by around $0.28 \%$ per year after accounting for inflation rate from 2004 to $2016,{ }^{19}$ which could not keep up with the rising housing price. The house price to median monthly household income ratio has increased from 6.0 in 2004 to 14.0 in $2019 .^{20}$ Although Hong Kong is the jurisdiction with the least affordable housing in the world, no studies have examined the association between housing affordability and health in Hong Kong.

This study aims to (1) examine the dose-response relationship of housing affordability, measured by the residual-income approach, with physical and mental health; and (2) assess the potential mediating role of deprivation of necessities on the association between housing affordability and health in Hong Kong.

\section{METHODS}

\section{Study design and participants}

Data were collected from a random sample of the addresses provided by the Census and Statistics Department (C\&SD) of the Hong Kong Government. A sample of 25000 addresses in 200 areas was obtained, based on the C\&SD sampling frame of living quarters (ie, residential dwellings). Using a two-stage stratified sample design, living quarters were first stratified by geographical area and then by type of living quarters. A domestic household is defined as a group of people who live together and make common provision for the essentials for living. A single adult respondent (aged 18 years or above) whose birthday was coming up next within each household was recruited. Face-toface survey interviews were conducted by trained interviewers using structured questionnaires from June 2014 to August 2015. With a response rate of $60.2 \%, 2282$ household respondents were successfully enumerated. Those who lacked information on age or sex $(n=3)$, and those who were randomly selected for the construction of the Deprivation Index (DI) $(n=301)$ were excluded, with 1978 respondents included in the multivariable analyses (figure 1).

\section{Measurements}

\section{Sociodemographic and socioeconomic factors}

Information on age, sex, marital status, education level, household size and housing type were collected. Marital status was categorised into 'married' (including cohabitation) or 'nonmarried' (including never married, divorced, separated or widowed), while education level was classified into 'primary or below', 'secondary' and 'tertiary or above'. We also collected self-reported flat size, which was taken as the midpoint of each of the 11 ordinal size bands, and household composition in terms of continuous numbers of adults and children within a household. Living space per capita, as a continuous variable, was then derived by dividing flat size by household size. Housing type included two dimensions-being in public or private housing, and the housing tenure (rental or ownership). It was categorised into 'public rental housing', 'public ownership housing', 'private rental housing' and 'private ownership housing'.

\section{Lifestyle behaviours}

Smoking status was categorised as 'non-smoker' and 'past/current smoker'. Alcohol drinking was categorised as 'non-risky' or 'risky'. Respondents scoring 5 or more out of 12 in the Alcohol Use Disorders Identification Test-Consumption were regarded as potentially risky drinkers. ${ }^{21}$ Physical activity was assessed by the International Physical Activity Questionnaire short-form, ${ }^{22}$ with three levels being classified, namely 'active', 'minimally active' and 'inactive'.
Housing affordability as primary predictor

To assess housing affordability, the residual-income approach was adopted. ${ }^{1}$ Data on monthly household income, in Hong Kong dollars (US\$1 $\approx \mathrm{HK} \$ 7.8$ ), were collected using self-reported questions with 36 income groups ranging from 'no income' to 'HK\$100000 or above'. The income level was taken as the midpoints of the 36 income bands. Continuous data on monthly mortgage repayments or rents were also reported by owner occupiers or renters. Based on the residual-income approach, ${ }^{1}$ housing affordability was derived by subtracting the monthly mortgage repayments or rents, if any, from monthly household income, which were then regrouped into four quartiles based on the posthousing residual income level.

\section{Deprivation as mediator}

While income-related measures are the most widely used indicators of poverty, they omit important aspects of it, such as nonmonetary resources or social barriers that hinder people from achieving the standard of living that is customary in a given society. ${ }^{23}$ Therefore, a 21-item DI was adopted to assess whether respondents could afford a range of items considered to be necessities by the majority of the adults in Hong Kong. For the construction of the DI, we first randomly selected 301 respondents and asked if they considered a range of items as necessities. Twenty-one items of which at least half of the respondents perceived as necessities were selected. Four items were measures of social deprivation, while 17 items were measures of material deprivation including 'food deprivation' ( 3 items), 'clothing deprivation' (3 items), 'medical care deprivation' (3 items), 'household facilities and equipment' (5 items), 'repair and maintenance' ( 2 items) and 'finance' ( 1 item). ${ }^{24}$ Then, we compared the mean DI scores among individuals in the ten deciles of equivalised household income. Weighting factors based on the distributions of age and sex of the mid-2014 Hong Kong population (online supplementary table 1 ) were applied to ensure the representativeness of our defined cut-off score of the DI. We found a much higher deprivation level in the lowest income decile (2.66) than that in the second and third deciles (1.55 and 1.32, respectively); hence, a DI score of 2 or above was considered 'deprived'. ${ }^{24}$ Details on the development, validity and reliability of the DI have been described previously. ${ }^{24}$

\section{Health-related quality of life as outcome}

Health-related quality of life was assessed using the 12-item Short-Form Health Survey version 2 (SF-12v2) validated for the Hong Kong Chinese population. ${ }^{25}$ Two distinct continuous summary scores were derived, including physical component summary (PCS) for physical health and mental component summary (MCS) for mental health. We applied a norm-based scoring algorithm with reference to data from a Hong Kong general population survey. ${ }^{26}$

\section{Statistical analysis}

Descriptive characteristics of respondents are presented as means with SD for continuous variables and as count data with percentages for categorical variables, with the numbers of missing values for each variable.

To account for the potential bias due to missing data, multiple imputation by chained equations were employed to generate the multiply imputed dataset by estimating plausible values for the missing data based on the distribution of the observed values. ${ }^{27}$ All missing values were filled in by simple random sampling with replacement from the observed values. The first variable with 


\section{Random sample of 25,000 addresses from C\&SD frame of living quarters}

\section{Two-stage stratified random sample}

- By geographical area

- By type of housing

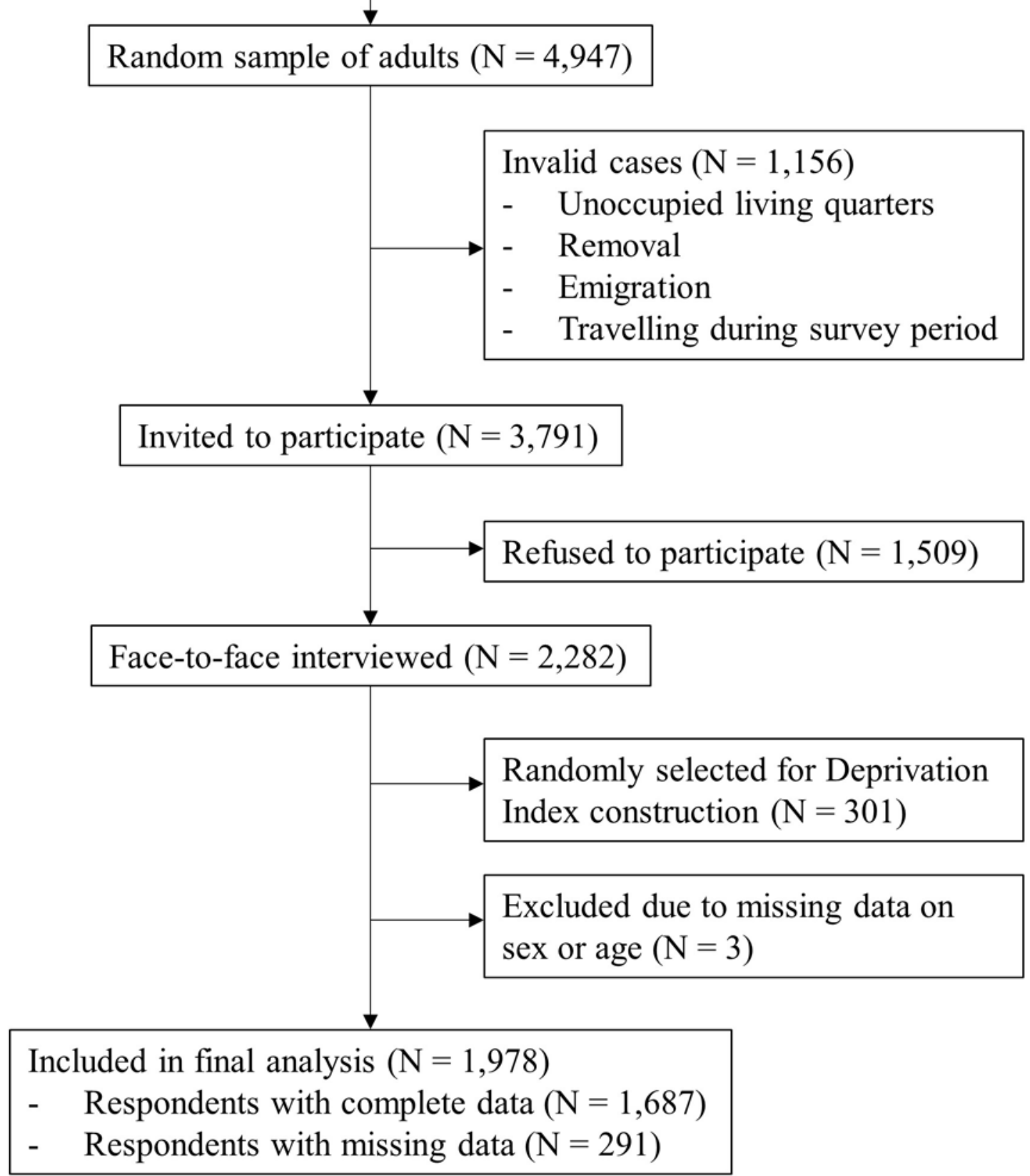

Figure 1 Flow chart on study design and sample selection. C\&SD, Census and Statistics Department.

missing values $\left(\mathrm{x}_{1}\right)$ was regressed on all other variables restricted to individuals with the observed $\mathrm{x}_{1}$. Missing values in $\mathrm{x}_{1}$ were then replaced by simulated draws from the posterior predictive distribution of $x_{1}$. Next, the second variable with missing values $\left(x_{2}\right)$ was regressed on all other variables restricted to individuals with the observed $\mathrm{x}_{2}$, using the imputed values of $\mathrm{x}_{1}$. Likewise, missing values in $\mathrm{x}_{2}$ were replaced by draws from the posterior predictive distribution of $x_{2}$. The process was repeated for all other variables with missing values. Depending on the variable types (ie, continuous, binary, ordinal and nominal), each variable was imputed using its own imputation model. In order to stabilise the results, the whole procedure was repeated for 20 times to give 20 imputed datasets. Missing value patterns analysis showed no particular obstacles to multiple imputation, and the descriptive characteristics 


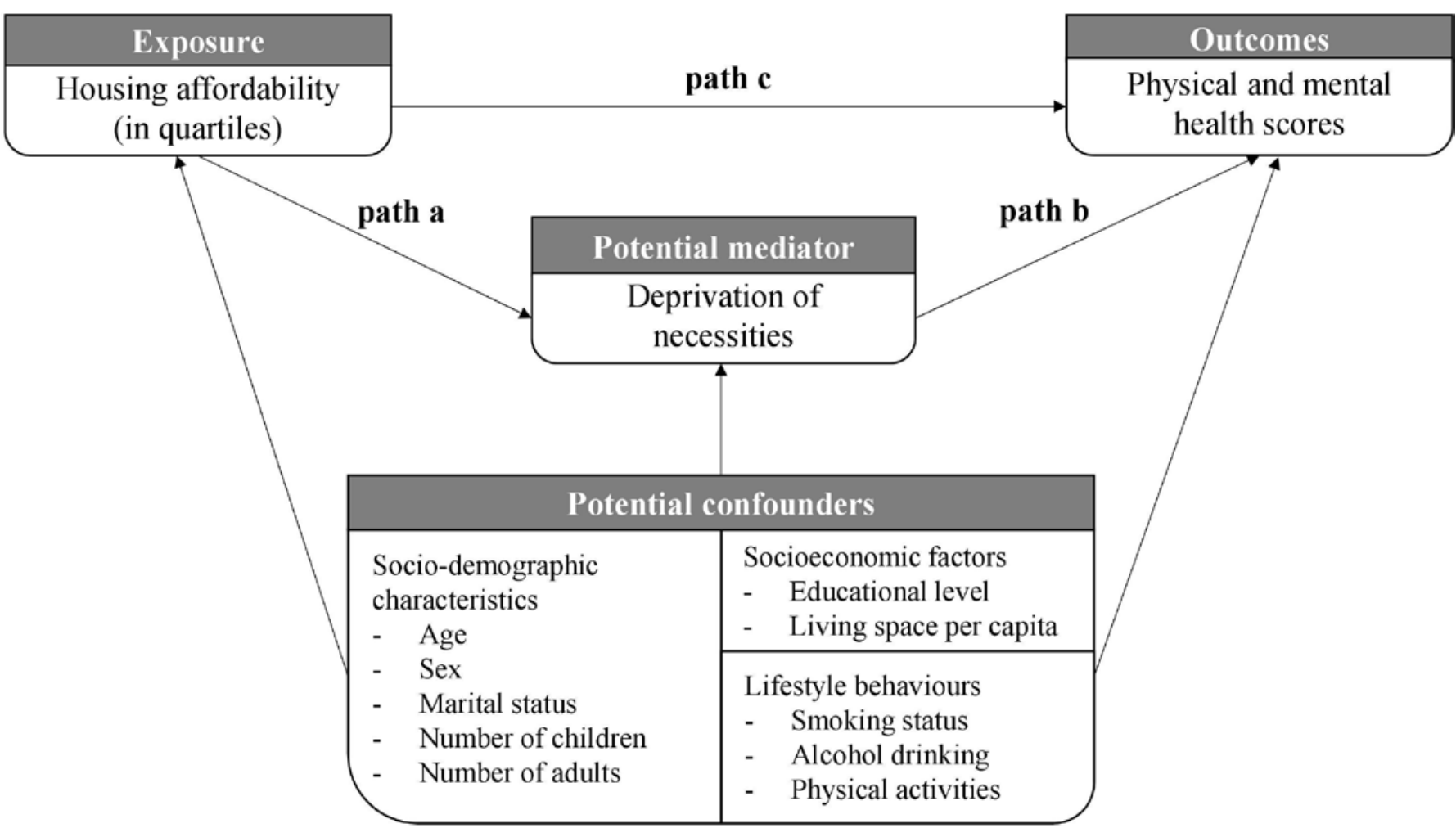

Figure 2 Simplified directed acyclic graph for the association between housing affordability and physical and mental health status, with the potential mediator and confounders. Path C illustrates the direct effect of housing affordability on health, while paths $A$ and $B$ describe the indirect effect of housing affordability on health through deprivation of necessities.

of the sample with missing data $(n=291)$ were similar to those without missing data $(n=1687)$ despite being slightly more likely to be female, less educated, deprived and living in public housing (online supplementary table 2). We found no indications of our data being 'missing not at random'.

Multivariable linear regressions were performed to assess the associations of housing affordability with PCS and MCS scores separately, controlling for all the sociodemographic, socioeconomic and lifestyle factors listed above. Figure 2 illustrates the simplified directed acyclic graph that represents the causal pathway between housing affordability and physical and mental health status, with the potential mediator and confounders. Model parameters were estimated in each of the 20 imputed datasets to obtain 20 completed-data estimates of coefficients and their variance-covariance matrix. The final estimates of coefficients and standard errors were then computed by applying combination rules by Little and Rubin $^{28}$ to the 20 completed-data estimates. No apparent violation of the normality and homoscedasticity assumptions was observed in the linear regression models. To ensure the representativeness of our results for the Hong Kong household population, a sensitivity analysis that applied weighting factors based on the distributions of age and sex of the mid-2014 population in Hong Kong was conducted (online supplementary table 1).

Mediation analyses were also conducted to assess the mediating role of deprivation on the effect of housing affordability on PCS or MCS. Specifically, we adopted the seemingly unrelated regression (SUR) model, ${ }^{29}$ which uses the asymptotically efficient, feasible, generalised least-squares algorithm for parameter estimation, ${ }^{30}$ to delineate the total effect of housing affordability on PCS or MCS by unpicking the direct effect (path c in figure 2) and indirect effect through deprivation (paths a and $b$ in figure 2). ${ }^{31} 32$ The SUR model was employed because it assumes contemporaneous cross-equation error correlation, ${ }^{29}$ which is common among the set of linear regression equations used for mediation analyses. Previous epidemiological research has also adopted the SUR model for mediation analyses. ${ }^{33}$ The SUR model is also well suited for estimating and comparing indirect effects in independent variables with multiple categories (ie, housing affordability in quartiles). In our SUR model, two sets of linear regression equations were simultaneously estimated: (1) the effect of the independent variable (ie, housing affordability) and potential confounders on the potential mediator (ie, deprivation); and (2) the effect of housing affordability, deprivation and potential confounders on the dependent variable (ie, PCS or MCS scores). All potential confounders used in the multivariable linear regression models were included in both sets of equations for the mediation analyses. The total indirect effect of housing affordability through deprivation was computed by first multiplying the $\beta$ coefficients of paths $\mathrm{a}$ and $\mathrm{b}$ for each of the three lower affordability quartiles and then adding up the three product terms (ie, the sum of $\mathrm{a}_{\mathrm{q} 1}{ }^{*} \mathrm{~b}, \mathrm{a}_{\mathrm{q} 2}{ }^{*} \mathrm{~b}$ and $\mathrm{a}_{\mathrm{q} 3}{ }^{*} \mathrm{~b}$, where $\mathrm{a}_{\mathrm{q} 1}$ $\mathrm{a}_{\mathrm{q} 2}$ and $\mathrm{a}_{\mathrm{q} 3}$ represent the $\beta$ coefficients of the first quartile, second quartile and third quartile, respectively, with reference to the highest affordability quartile, against deprivation). ${ }^{31}$ We used the statistical approach according to the Rubin's rules to compute the total indirect effect for each imputed dataset and pool them. ${ }^{28}$ The total effect represents the sum of $\beta$ coefficients of each of the three lower housing affordability quartiles with reference to the highest affordability quartile (ie, the sum of $\beta$ coefficient between first and fourth quartiles, $\beta$ coefficient between second and fourth quartiles and $\beta$ coefficient between third and fourth quartiles), which is also equivalent to the sum of total direct effect and total indirect effect. The standard errors of the total effect and total indirect effect were computed using the delta method. ${ }^{32}$ The ratio of total indirect effect to total effect was used to assess the relative importance 
Table 1 Characteristics of subjects $(n=1978)$

\begin{tabular}{|c|c|c|c|c|c|}
\hline \multirow[b]{2}{*}{ Characteristic } & \multirow[b]{2}{*}{ Total } & \multicolumn{4}{|c|}{ Posthousing residual income by quartiles ${ }^{a}$} \\
\hline & & $\begin{array}{l}\text { First quartile } \\
(<\$ 11000)\end{array}$ & $\begin{array}{l}\text { Second quartile } \\
\text { (\$11 000-\$18 999) }\end{array}$ & $\begin{array}{l}\text { Third quartile } \\
\text { (\$19 000-\$28 999) }\end{array}$ & $\begin{array}{l}\text { Fourth quartile } \\
(\geq \$ 29000)\end{array}$ \\
\hline \multicolumn{6}{|l|}{ Health-related quality of life } \\
\hline Physical component summary ${ }^{b}$ & $51.5 \pm 9.0$ & $49.5 \pm 10.4$ & $51.0 \pm 9.0$ & $52.8 \pm 7.9$ & $53.1 \pm 8.0$ \\
\hline Mental component summary ${ }^{c}$ & $54.9 \pm 8.5$ & $52.1 \pm 8.1$ & $54.3 \pm 8.6$ & $55.6 \pm 8.5$ & $57.0 \pm 8.0$ \\
\hline \multicolumn{6}{|l|}{ Sociodemographic characteristics } \\
\hline Age (years) & $51.6 \pm 17.7$ & $60.7 \pm 17.1$ & $51.0 \pm 15.9$ & $47.7 \pm 15.9$ & $46.2 \pm 16.7$ \\
\hline \multicolumn{6}{|l|}{ Sex } \\
\hline Male & $814(41.2)$ & $189(41.9)$ & $162(37.5)$ & $186(41.4)$ & $203(46.1)$ \\
\hline Female & $1164(58.8)$ & $262(58.1)$ & $270(62.5)$ & $263(58.6)$ & $237(53.9)$ \\
\hline \multicolumn{6}{|l|}{ Marital status ${ }^{d}$} \\
\hline Married/cohabit & $1257(63.7)$ & $209(46.7)$ & $308(71.3)$ & $320(71.3)$ & $299(68.0)$ \\
\hline Single/divorced/separated/widowed & $717(36.3)$ & $239(53.3)$ & $124(28.7)$ & $129(28.7)$ & $141(32.0)$ \\
\hline Number of children ${ }^{e}$ & $0.6 \pm 0.9$ & $0.4 \pm 0.7$ & $0.9 \pm 1.0$ & $0.8 \pm 0.9$ & $0.6 \pm 0.8$ \\
\hline Number of adults ${ }^{\dagger}$ & $2.7 \pm 1.2$ & $1.7 \pm 0.8$ & $2.4 \pm 0.8$ & $2.9 \pm 1.0$ & $3.5 \pm 1.2$ \\
\hline \multicolumn{6}{|l|}{ Socioeconomic factors } \\
\hline \multicolumn{6}{|l|}{ Educational level ${ }^{g}$} \\
\hline Primary or below & $630(32.0)$ & $224(49.8)$ & $144(33.6)$ & $101(22.6)$ & $76(17.4)$ \\
\hline Secondary & $1046(53.2)$ & $197(43.8)$ & $253(59.1)$ & $279(62.4)$ & $236(54.1)$ \\
\hline Tertiary or above & $290(14.8)$ & $29(6.4)$ & $31(7.2)$ & $67(15.0)$ & $124(28.4)$ \\
\hline \multicolumn{6}{|l|}{ Deprivation $^{\text {h }}$} \\
\hline Non-deprived & $1596(80.7)$ & $281(62.3)$ & $334(77.3)$ & $406(90.4)$ & $423(96.4)$ \\
\hline Deprived & $381(19.3)$ & $170(37.7)$ & $98(22.7)$ & $43(9.6)$ & $16(3.6)$ \\
\hline \multicolumn{6}{|l|}{ Housing type $^{i}$} \\
\hline Public rental housing & $1026(52.3)$ & $255(57.3)$ & $281(65.5)$ & $259(57.9)$ & $124(28.3)$ \\
\hline Public ownership housing & $344(17.5)$ & $49(11.0)$ & $40(9.3)$ & $69(15.4)$ & $119(27.2)$ \\
\hline Private rental housing & $181(9.2)$ & $59(13.3)$ & $46(10.7)$ & $33(7.4)$ & $35(8.0)$ \\
\hline Private ownership housing & $411(20.9)$ & $82(18.4)$ & $62(14.5)$ & $86(19.2)$ & $160(36.5)$ \\
\hline Living space per capita $^{j}$ & $15.4 \pm 9.5$ & $19.1 \pm 12.8$ & $13.9 \pm 8.1$ & $13.5 \pm 7.3$ & $15.5 \pm 8.4$ \\
\hline \multicolumn{6}{|l|}{ Lifestyle behaviours } \\
\hline \multicolumn{6}{|l|}{ Smoking status ${ }^{\mathrm{k}}$} \\
\hline Non-smoker & $1615(81.8)$ & $360(79.8)$ & $342(79.4)$ & $367(82.1)$ & $368(83.6)$ \\
\hline Past smoker/current smoker & $360(18.2)$ & $91(20.2)$ & $89(20.6)$ & $80(17.9)$ & $72(16.4)$ \\
\hline \multicolumn{6}{|l|}{ Alcohol drinking' } \\
\hline Non-risky drinker & 1892 (96.6) & $440(98.0)$ & $409(95.8)$ & $424(95.3)$ & $420(96.8)$ \\
\hline Risky drinker & $67(3.4)$ & $9(2.0)$ & $18(4.2)$ & $21(4.7)$ & $14(3.2)$ \\
\hline \multicolumn{6}{|l|}{ Physical activities } \\
\hline Active & $217(11.0)$ & $51(11.3)$ & $45(10.4)$ & $51(11.4)$ & $49(11.1)$ \\
\hline Minimally active & $279(14.1)$ & $85(18.8)$ & $64(14.8)$ & $49(10.9)$ & 49 (11.1) \\
\hline Inactive & $1482(74.9)$ & $315(69.8)$ & $323(74.8)$ & $349(77.7)$ & $342(77.7)$ \\
\hline
\end{tabular}

Data are presented as $\mathrm{n}(\%)$ or mean \pm SD.

Missing data: ${ }^{\mathrm{a}} 206 ;{ }^{\mathrm{b}} 45 ;{ }^{\mathrm{c}} 45 ;{ }^{\mathrm{d}} 4 ;{ }^{\mathrm{e}} 1 ;{ }^{\mathrm{f}} 1 ;{ }^{\mathrm{g}} 12 ;{ }^{\mathrm{h}} 1 ;{ }^{\mathrm{i}}{ }^{1} 6 ;{ }^{\mathrm{j}} 2{ }^{2}{ }^{\mathrm{k}} 3 ;{ }^{\mathrm{l}} 19$.

US\$1 $\approx$ HK\$7.8.

of the mediating role of deprivation on the association between housing affordability and PSC or MCS.

The statistical packages SPSS V.21 and Stata V.14 were used for the analyses.

\section{RESULTS}

Characteristics of respondents are illustrated in table 1. Respondents with poorer housing affordability were more likely to be older, non-married, less educated, less physically active, smokers and renters especially of public housing. They also tended to have worse physical and mental health. Almost two out of every five $(37.7 \%)$ respondents in the poorest housing affordability quartile were deprived, which was about 10 times higher than the 3.6\% who were deprived in the greatest housing affordability quartile.

The associations of housing affordability with both PCS and MCS scores are presented in table 2. In general, dose-response relationships are observed. After adjusting for sociodemographic, socioeconomic and lifestyle factors, respondents in the lower housing affordability quartiles tended to have poorer mean PCS scores $(\beta$ (95\% CI): $-2.53(-4.05$ to -1.01$),-2.23$ $(-3.54$ to -0.92$),-0.64(-1.80$ to 0.51$)$ for the first, second and third quartiles, respectively) and poorer mean MCS scores ( $\beta$ (95\% CI): -3.87 ( -5.30 to -2.45$),-2.35(-3.59$ to -1.11$)$, $-1.28(-2.40$ to -0.17$)$ for the first, second and third quartiles, 
Table 2 The associations of housing affordability with physical component summary and mental component summary

\begin{tabular}{|c|c|c|c|c|}
\hline \multirow[b]{2}{*}{ Characteristics } & \multicolumn{2}{|c|}{ Physical component summary } & \multicolumn{2}{|c|}{ Mental component summary } \\
\hline & $\beta$ coefficient $(95 \% \mathrm{Cl})^{*}$ & $P$ value & $\beta$ coefficient $(95 \% \mathrm{Cl})^{*}$ & P value \\
\hline \multicolumn{5}{|l|}{ Housing affordability } \\
\hline \multicolumn{5}{|l|}{ Posthousing residual income } \\
\hline Fourth quartile (highest housing affordability) & Ref. & & Ref. & \\
\hline Third quartile & $-0.64(-1.80$ to 0.51$)$ & 0.275 & $-1.28(-2.40$ to -0.17$)$ & 0.024 \\
\hline Second quartile & $-2.23(-3.54$ to -0.92$)$ & 0.001 & $-2.35(-3.59$ to -1.11$)$ & $<0.001$ \\
\hline First quartile (lowest housing affordability) & $-2.53(-4.05$ to -1.01$)$ & 0.001 & $-3.87(-5.30$ to -2.45$)$ & $<0.001$ \\
\hline \multicolumn{5}{|l|}{ Sociodemographic characteristics } \\
\hline Age (per year increase) & $-0.13(-0.17$ to -0.10$)$ & $<0.001$ & $-0.10(-0.13$ to -0.07$)$ & $<0.001$ \\
\hline \multicolumn{5}{|l|}{ Sex } \\
\hline Male & Ref. & & Ref. & \\
\hline Female & 1.55 (0.67 to 2.44$)$ & 0.001 & $-0.69(-1.53$ to 0.15$)$ & 0.108 \\
\hline \multicolumn{5}{|l|}{ Marital status } \\
\hline Married/cohabit & Ref. & & Ref. & \\
\hline Single/divorced/separated/widowed & $-1.24(-2.13$ to -0.34$)$ & 0.007 & $-1.53(-2.39$ to -0.67$)$ & $<0.001$ \\
\hline \multicolumn{5}{|l|}{ Socioeconomic factors } \\
\hline \multicolumn{5}{|l|}{ Educational level } \\
\hline Tertiary or above & Ref. & & Ref. & \\
\hline Secondary & $1.18(-0.08$ to 2.44$)$ & 0.066 & $0.41(-0.79$ to 1.61$)$ & 0.506 \\
\hline Primary or below & $0.84(-0.74$ to 2.42$)$ & 0.299 & $-0.11(-1.62$ to 1.40$)$ & 0.887 \\
\hline \multicolumn{5}{|l|}{ Housing type } \\
\hline Public rental housing & Ref. & & Ref. & \\
\hline Public ownership housing & $-0.55(-1.70$ to 0.60$)$ & 0.346 & $0.02(-1.08$ to 1.12$)$ & 0.974 \\
\hline Private rental housing & $0.19(-1.20$ to 1.58$)$ & 0.788 & $1.21(-0.11$ to 2.53$)$ & 0.072 \\
\hline Private ownership housing & $-0.56(-1.76$ to 0.64$)$ & 0.359 & $0.33(-0.79$ to 1.45$)$ & 0.564 \\
\hline Living space per capita (per $10 \mathrm{~m}^{2}$ increase) & $-0.18(-0.73$ to 0.37$)$ & 0.522 & $-0.05(-0.57$ to 0.48$)$ & 0.864 \\
\hline Number of children (per one child increase) & $-0.41(-0.94$ to 0.11$)$ & 0.121 & $-0.93(-1.43$ to -0.44$)$ & $<0.001$ \\
\hline Number of adults (per one adult increase) & $-0.24(-0.69$ to 0.21$)$ & 0.290 & $-0.39(-0.82$ to 0.04$)$ & 0.078 \\
\hline \multicolumn{5}{|l|}{ Lifestyle factors } \\
\hline \multicolumn{5}{|l|}{ Smoking status } \\
\hline Non-smoker & Ref. & & Ref. & \\
\hline Past smoker/current smoker & $-0.05(-1.18$ to 1.08$)$ & 0.933 & $-0.81(-1.88$ to 0.26$)$ & 0.139 \\
\hline \multicolumn{5}{|l|}{ Alcohol drinking } \\
\hline Non-risky drinker & Ref. & & Ref. & \\
\hline Risky drinker & $-0.16(-2.36$ to 2.05$)$ & 0.889 & $-2.87(-4.96$ to -0.77$)$ & 0.007 \\
\hline \multicolumn{5}{|l|}{ Physical activities } \\
\hline Active & Ref. & & Ref. & \\
\hline Minimally active & $-0.29(-1.85$ to 1.26$)$ & 0.711 & 0.70 ( -0.78 to 2.19$)$ & 0.353 \\
\hline Inactive & $-2.14(-3.38$ to -0.89$)$ & 0.001 & $-0.25(-1.44$ to 0.94$)$ & 0.680 \\
\hline
\end{tabular}

${ }^{*} \beta$ coefficients of all listed variables were mutually adjusted in the corresponding models.

$\mathrm{Cl}$, Confidence interval .

respectively), when compared with those in the greatest housing affordability (fourth) quartile. Being older, female, neither married nor cohabitating and physically inactive were associated with poorer PCS, whereas being older, neither married nor cohabitating, a risky drinker and having more children in the household were associated with poorer MCS. Consistent patterns were observed after weighting factors by age and sex were applied (online supplementary table 3 ).

Regarding the mediating role of deprivation of necessities on the association of housing affordability with health, results showed that about a third (34.3\%) of the impact of housing affordability on PCS $(\mathrm{p}<0.001)$ and almost one-sixth $(15.8 \%)$ of that on MCS $(\mathrm{p}<0.001)$ were mediated by deprivation (table 3$)$.

\section{DISCUSSION}

To our knowledge, this is the first study in Hong Kong or any Asian population that examines the association of housing affordability with general physical and mental health. In general, there were dose-response associations of housing affordability with both physical and mental health-that is, the lower the housing affordability, the worse the physical and mental health. Despite taking into account the effects of other sociodemographic, socioeconomic and lifestyle factors, housing affordability stress still independently poses threat to both physical and mental health, and the association with mental health was particularly strong. We also found significant indirect effects of deprivation on the 
Table 3 Mediation analyses of deprivation on the effect of housing affordability on physical component summary and mental component summary

\begin{tabular}{llllll}
\hline & Physical component summary & & & Mental component summary \\
\cline { 2 - 3 } & $\boldsymbol{\beta}$ coefficient $(95 \% \mathrm{Cl})$ & $\boldsymbol{P}$ value & & $\boldsymbol{\beta}$ coefficient $(95 \% \mathrm{Cl})$ & $\boldsymbol{P}$ value \\
\hline Indirect effect through deprivation & $-1.85(-2.58$ to -1.12$)$ & $<0.001$ & & $-1.18(-1.79$ to -0.57$)$ & $<0.001$ \\
Total effect & $-5.41(-8.77$ to -2.04$)$ & 0.002 & & $-7.51(-10.70$ to -4.31$)$ & $<.001$ \\
Proportion mediated through deprivation $(\%)^{*}$ & 34.3 & - & 15.8 & - \\
\hline
\end{tabular}

${ }^{*}$ Calculated by $\beta$ coefficient of indirect effect divided by $\beta$ coefficient of total effect.

$\mathrm{Cl}$, Confidence interval

association of housing affordability with both physical and mental health in the mediation models, in which proportion of effect mediated through deprivation was larger for physical health $(34.3 \%)$ than for mental health (15.8\%).

\section{Housing affordability, deprivation and health}

There may be several explanations for our main findings. As our measurement of housing affordability being a posthousing residual income implies, high housing cost could induce stress by reducing available income for posthousing expenditures. ${ }^{19}$ Nevertheless, on top of income, liquid assets are also often used by people for their daily expenses, but such information is difficult to obtain in survey interviews. Therefore, deprivation, which measures the lack of command over sufficient resources over time to afford the social and material necessities of life,${ }^{34}$ was conceived to give a more comprehensive and multidimensional picture of the social and material circumstances of the individuals beyond the conventional income measure of poverty. In fact, it has been shown that there was only low overlap between income and deprivation in measuring poverty. ${ }^{35} 36$ By making use of deprivation in our mediation analysis, we were also able to show that at least partially the effect of housing affordability on health was mediated through a lack of command over resources, even after paying off the housing expenses. This is also consistent with a previous study that deprivation is found to be associated with physical and mental health beyond income poverty. ${ }^{24}$

However, the above-mentioned explanations may still be only part of a bigger story since the mediation effects of deprivation were partial. In fact, high housing cost itself can be a major source of stress beyond the effects brought by depletion of available resources for posthousing expenditures (whether income or deprivation), especially in Hong Kong where the housing affordability stress is the greatest in the world. For instance, poor housing affordability may be reflective of the total amount spent on housing (ie, mortgages and/or rents) over one's lifetime, the duration of making housing expenses over a prolonged period in one's lifetime, the stress associated with long-term mortgage debt as well as the stress of securing employments and/or income sources (eg, salary, business or investment) that can sustain the kind of lifestyle, quality of life and housing standard that one leads over one's lifetime. Consistently, studies have shown that long-term debt and mortgage debt are associated with poorer health, particularly mental health, outcomes. ${ }^{37-39}$ Moreover, housing affordability may negatively affect the physical health through psychosocial stress responses which in turn could lead to worse physical health through allostatic load. ${ }^{40}$

\section{Limitations}

Novel to this study was the adoption of the residual-income approach, instead of the conventional ratio-income approach to define housing affordability, which is more reflective of the actual financial burden to meet other expenditure needs after paying for housing. However, there are caveats to our study. First, the analyses were cross-sectional and thus we have not established any temporal relationship between housing affordability and health, and meaningful changes in outcomes of clinical importance cannot be derived. Second, survey questions were all self-reported, which may result in some recall bias. Third, there may be selection bias since the sampled participants tended to be female, less skilled, aged and stayed at home during office hours. As 1509 invited adults (39.8\%) refused to participate in our study, we could not rule out the possibility of volunteer bias that these people may differ substantially from those who agreed to participate. Nonetheless, our results remained consistent after applying weighting factors based on the age and sex distribution of the general Hong Kong population in mid-2014, showing that our findings are unbiased and generalisable to the population of Hong Kong (online supplementary table 3). Moreover, overrepresentation or under-representation of certain sampling areas might potentially exist since the single-age population data by district was not available for geographical weighting. Fourth, a subset of the sample was enumerated with missing data; however, multiple imputation was applied and we found similar results. Lastly, since we focused on housing affordability in this study, we did not focus on other factors associated with health. Also, in spite of the effect of unaffordable housing on health, previous studies have shown that the association may not be universal across all social groups, ${ }^{5} 84$ and that there may be interactions between housing affordability and housing types. ${ }^{42}$ For example, given that almost half of the population are low-income households eligible for public rental housing and subsidised home ownership housing in Hong Kong, ${ }^{43}$ lowincome households may not have a relatively higher housing cost burden per se. Nevertheless, we may not have enough power to conduct this analysis in this current study. All these warrant further investigations in future studies.

\section{CONCLUSION}

To improve the health of the Hong Kong population, the problem of housing affordability should be targeted. Additionally, deprived individuals should also be targeted for any intervention or policy to tackle health inequality as deprivation of necessities helps exacerbate the problems of unaffordable housing costs. Since housing affordability tends to be a more upstream factor than deprivation in the pathway to health status, strategies and policies to tackle the housing issue are important. Jurisdictions around the world should take the example of Hong Kong as a major lesson if they aim to eliminate health inequalities-even in a rich society with publicly available healthcare services and high levels of 
public housing provision like Hong Kong, allowing housing costs to rise too high has negative health consequences for the population.

\section{What is already known on this subject}

- Poor housing affordability has been suggested to affect physical and mental health, but most previous studies used the ratio-income approach in defining housing affordability, while a residual-income approach may be more reflective of the actual financial burden to meet other expenditure needs after paying for housing.

- Asian populations are facing increasingly severe housing affordability stress, but few studies have investigated its association with health.

- Hong Kong has the world's worst housing affordability problem, but no studies have investigated its association with health.

\section{What this study adds}

- Using the residual-income approach, we found doseresponse relationships of housing affordability with physical and mental health in Hong Kong.

- We found evidence of partial mediation by deprivation of necessities on the relationship between housing affordability and health.

- Targeting deprived individuals to reduce their housing affordability stress may have great potential in improving population health and reducing health inequality.

\section{Twitter Roger Yat-Nork Chung @rogerynchung}

Contributors RY-NC oversaw the whole study and was responsible for literature review, study design, data collection, data interpretation and write-up of the manuscript; GK-KC was mainly responsible for literature review, data analysis, data interpretation and write-up of the manuscript; DG contributed to the data analysis, data interpretation and commenting on write-up; JK-LM contributed to write-up of the manuscript; L-FZ contributed to literature review and write-up of the manuscript; DC contributed to data analysis and data interpretation; FTTL contributed to data interpretation and commenting on write-up; SY-SW participated in the study design, data collection and data interpretation; HW was responsible for study design and data collection. All authors read and approved the final manuscript.

Funding This work was supported by a Grant from the Central Policy Unit of the Government of the Hong Kong Special Administrative Region and the Research Grants Council of the Hong Kong Special Administrative Region, China (Project No. 4003-SPPR-11).

Competing interests None declared.

Patient consent for publication Not required.

Ethics approval This study has been approved by the Survey and Behavioural Research Ethics Committee of the Chinese University of Hong Kong in June 2012.

Provenance and peer review Not commissioned; externally peer reviewed. Data availability statement No data are available.

Open access This is an open access article distributed in accordance with the Creative Commons Attribution Non Commercial (CC BY-NC 4.0) license, which permits others to distribute, remix, adapt, build upon this work non-commercially, and license their derivative works on different terms, provided the original work is properly cited, appropriate credit is given, any changes made indicated, and the use is non-commercial. See: http://creativecommons.org/licenses/by-nc/4.0/.

\section{ORCID iDs}

Roger Yat-Nork Chung http://orcid.org/0000-0003-4407-8208

Gary Ka-Ki Chung http://orcid.org/0000-0002-8652-212X

Francisco Tsz Tsun Lai http://orcid.org/0000-0002-9121-1959

\section{REFERENCES}

1 Stone ME. What is housing affordability? the case for the residual income approach. Hous Policy Debate 2006;17:151-84.

2 Stahre M, VanEenwyk J, Siegel P, et al. Housing insecurity and the association with health outcomes and unhealthy behaviors, Washington state, 2011. Prev Chronic Dis 2015;12:E109

3 Meltzer R, Schwartz A. Housing affordability and health: evidence from New York City. Hous Policy Debate 2016;26:80-104.

4 Alley DE, Soldo BJ, Pagán JA, et al. Material resources and population health: disadvantages in health care, housing, and food among adults over 50 years of age. Am J Public Health 2009:99:5693-701.

5 Pollack CE, Griffin BA, Lynch J. Housing affordability and health among homeowners and renters. Am J Prev Med 2010;39:515-21.

6 Taylor MP, Pevalin DJ, Todd J. The psychological costs of unsustainable housing commitments. Psychol Med 2007;37:1027-36.

7 Bentley R, Baker E, Mason K. Cumulative exposure to poor housing affordability and its association with mental health in men and women. J Epidemiol Community Health 2012;66:761-6.

8 Bentley R, Baker E, Mason K, et al. Association between housing affordability and mental health: a longitudinal analysis of a nationally representative household survey in Australia. Am J Epidemiol 2011;174:753-60.

9 Housing DJR. And health inequalities: review and prospects for research. Hous Stud 2000;15:341-66.

10 Kirkpatrick SI, Tarasuk V. Housing circumstances are associated with household food access among low-income urban families. J Urban Health 2011;88:284-96.

11 Hernández D. Affording housing at the expense of health: exploring the housing and neighborhood strategies of poor families. J Fam Issues 2016;37:921-46.

12 Jewkes M, Delgadillo L. Weaknesses of housing affordability indices used by practitioners. J Financ Couns Plan 2010;21:43-53.

13 Stone ME. The residual income approach to housing affordability: the theory and the practice (with Terry Burke and Liss Ralston), 2011. Available: https://works.bepress. com/michael_stone/7/

14 Bertaud A. 15Th annual Demographia international housing affordability survey: 2019. St Louis, USA: Demographia, 2019. Available: http://www.demographia.com/ dhi.pdf

15 Hui E, Seabrooke W. Dynamic impact of land supply on population mobility with evidence from Hong Kong. Pacific Rim Property Research Journal 2003;9:45-60.

16 Census and Statistics Department. Population estimates. Hong Kong, 2018.

17 Task Force on Land Supply. Insufficient land supply leading to imbalance in supplydemand. Hong Kong, 2018.

18 Rating and Valuation Department. Private Domestic - Completions, Stock, Vacancy and Take-up. Hong Kong, 2016

19 The Hong Kong Federation of Trade Union. [Concerning the minimal actual wage increase among employees] (in Chinese), 2018. Available: https://www.legco.gov.hk/ yr17-18/chinese/panels/mp/papers/mp20180320cb2-1036-6-c.pdf

20 Realty M, Index AP, 2019. Available: https://en.midland.com.hk/property-price-chart [Accessed 17 Oct 2019].

21 BHK Y, Chung RY, Chung VCH, et al. Is alcohol use disorder identification test (audit) or its shorter versions more useful to identify risky drinkers in a Chinese population? a diagnostic study. PLoS One 2015;10:e0117721.

22 Craig C, Marshall A, Sjöström M, et al. International physical activity questionnaire: 12 -country reliability and validity. Medicine \& Science in Sports \& Exercise 2003;35:1381-95.

23 Wong $\mathrm{H}$, Saunders P, Wong WP, et al. Report of research study on deprivation and social exclusion in Hong Kong. Hong Kong, 2012.

24 Chung RY-N, Chung GK-K, Gordon D, et al. Deprivation is associated with worse physical and mental health beyond income poverty: a population-based household survey among Chinese adults. Qual Life Res 2018;27:2127-35.

25 Lam ETP, Lam CLK, Fong DYT, et al. Is the SF-12 version 2 health survey a valid and equivalent substitute for the SF-36 version 2 health survey for the Chinese? J Eval Clin Pract 2013;19:200-8

26 Lam CLK, Tse EYY, Gandek B. Is the standard SF-12 health survey valid and equivalent for a Chinese population? Qual Life Res 2005;14:539-47.

27 White IR, Royston P, Wood AM. Multiple imputation using chained equations: issues and guidance for practice. Stat Med 2011;30:377-99.

28 Little RJA, Rubin DB. Statistical analysis with missing data. Hoboken, NJ, USA: John Wiley \& Sons, Inc, 2002

29 Zellner A. An efficient method of estimating seemingly unrelated regressions and tests for aggregation bias. J Am Stat Assoc 1962;57:348-68.

30 Greene WH. Econometric analysis. NJ, USA: Prentice Hall, 2012.

31 UCLA. How can I do mediation analysis with a categorical IV in Stata? Available: https://stats.idre.ucla.edu/stata/faq/how-can-i-do-mediation-analysis-with-acategorical-iv-in-statal [Accessed 17 Oct 2019].

32 UCLA. How can I compute indirect effects with imputed data? (method 2) | Stata FAQ. Available: https://stats.idre.ucla.edu/stata/faq/how-can-i-compute-indirect-effectswith-imputed-data-method-2/ [Accessed 17 Oct 2019]. 
33 Lee B, Jeong S, Roh M. Association between body mass index and health outcomes among adolescents: the mediating role of traditional and cyber bullying victimization. BMC Public Health 2018;18:674.

34 Townsend P. Deprivation. J Soc Policy 1987;16:125-46.

35 Saunders P, Wong H, Wong WP. Deprivation and poverty in Hong Kong. Soc Policy Adm 2014:48:556-75.

36 Lau M, Gordon D. Poverty in a rich Society: the case of Hong Kong. Hong Kong: The Chinese University Press, 2017.

37 Richardson T, Elliott P, Roberts R. The relationship between personal unsecured debt and mental and physical health: a systematic review and meta-analysis. Clin Psychol Rev 2013;33:1148-62

38 Turunen E, Hiilamo H. Health effects of indebtedness: a systematic review. BMC Public Health 2014;14:489.
39 Fitch C, Hamilton S, Bassett P, et al. The relationship between personal debt and mental health: a systematic review. Ment Heal Rev J 2011;16:153-66.

40 McEWEN BS, Seeman T. Protective and damaging effects of mediators of stress: elaborating and testing the concepts of allostasis and allostatic load. Ann N Y Acad Sci 1999;896:30-47.

41 Mason KE, Baker E, Blakely T, et al. Housing affordability and mental health: does the relationship differ for renters and home purchasers? Soc Sci Med 2013:94:91-7.

42 Bentley RJ, Pevalin D, Baker E, et al. Housing affordability, tenure and mental health in Australia and the United Kingdom: a comparative panel analysis. Housing Studies 2016:31:208-22.

43 Census and Statistics Department. Quarterly report on general household survey (first quarter 2018). Hong Kong, 2018 